\title{
ANALISIS NERACA AIR DAERAH ALIRAN SUNGAI BOLANGO
}

\author{
Disusun Oleh : \\ Syafrudin Mopangga ${ }^{1}$, Siti Fatimawati ${ }^{2}$, Nona Fitriana Madjowa ${ }^{2}$ \\ ${ }^{123}$ STITEK Bina Taruna Gorontalo \\ bukustitek@yahoo.com
}

\begin{abstract}
ABSTRAK
Air bertransformasi melalui daur hidrologi yang dikenal sebagai sistim hidrologi dan pada Daerah Aliran Sungai (DAS) air diterima dari curah hujan yang kemudian memprosesnya sesuai dengan karakteristiknya menjadi aliran. Degradasi dan kerusakan sistem hidrologi DAS merupakan salah satu aspek kekritisan daerah aliran sungai, salah satu kerusakan sistem hidrologi DAS adalah terjadinya kekurangan air di musim kering dan meluapnya air pada musim penghujan. Untuk mengetahui kebutuhan air di daerah aliran sungai Bolango, jumlah besar debit ketersediaan air di daerah aliran sungai Bolango dan neraca air di daerah aliran sungai Bolango. Tahapan penelitian melalui Pengambilan Data, Analisa Curah Hujan, Analisa Debit Air, Perhitungan Kebutuhan Air dan Perhitungan Analisis Neraca Air DAS Bolango. Debit minimum pada bulan september dan debit maksimum pada bulan april. Untuk memenuhi kebutuhan air domestik dan non domestik masyarakat terutama yang ada di derah Kota Gorontalo perhitungan ketersediaan air ini sangat diperlukan untuk menentukan neraca air pada Daerah Aliran Sungai Bolango. 1. Debit inflow berkisar antara : $14,42 \mathrm{~m}^{3} /$ detik s/d $26,15 \mathrm{~m}^{3}$ /detik, 2. Debit inflow maksimum (Desember) : $26,15 \mathrm{~m}^{3} /$ detik, 3. Debit inflow minimum (September) : 14,42 $\mathrm{m}^{3} /$ detik.
\end{abstract}

Kata Kunci: Hidrologi, Curah Hujan, Debit Air, \& Neraca Air

\section{PENDAHULUAN}

Kebutuhan air oleh seluruh makhluk hidup merupakan suatu kebutuhan yang tidak akan terpisahkan dalam kehidupan sehari-hari, air merupakan sumber daya alam esensial yang sangat dibutuhkan oleh manusia dan makhluk hidup lainnya, dengan air maka bumi menjadi planet dalam tata surya yang memiliki kehidupan (Kodoatie, J. dan Sjarief, R. 2010). Air bertransformasi melalui daur hidrologi yang dikenal sebagai sistim hidrologi dan pada Daerah Aliran Sungai (DAS) air diterima dari curah hujan yang kemudian memprosesnya sesuai dengan karakteristiknya menjadi aliran. Hujan yang jatuh dalam satu DAS sebagian akan jatuh pada permukaan vegetasi, permukaan tanah atau badan air (Triatmodjo. B. 2009).

Analisis hidrologi bertujuan untuk menghitung potensi air yang ada pada daerah tertentu, dan bisa dimanfaatkan, dikembangkan serta mengatur potensi air untuk kepentingan masyarakat di sekitar daerah tersebut. Sebagian besar masalah yang selama ini dijumpai dalam analisis hidrologi yakni banyaknya cara dan model dalam penelitian hidrologi yang sudah barang tentu satu dengan yang lain menggunakan metode dengan hasil yang berbeda - beda. Sementara itu degradasi dan 
kerusakan sistem hidrologi DAS merupakan salah satu aspek kekritisan daerah aliran sungai, salah satu kerusakan sistem hidrologi DAS adalah terjadinya kekurangan air di musim kering dan meluapnya air pada musim penghujan. Penyebabnya dapat berupa penyimpangan musim, tipe iklim pada suatu daerah, kemampuan daerah aliran sungai dalam menyimpan air, adanya sedimentasi seperti bendung, danau maupun rawa serta adanya peningkatan kebutuhan air untuk berbagai keperluan akibat perkembangan jumlah penduduk dan kegiatan ekonomi yang sangat pesat disegala bidang, baik kebutuhan air untuk domestik, non domestik maupun untuk irigasi semuanya secara langsung akan berpengaruh pada keseimbangan air. Sungai Bolango merupakan sungai yang melintasi beberapa wilayah di Provinsi Gorontalo dan melewati tepat di tengah Kota Gorontalo yang merupakan hilir sungai dimana airnya mengalir sepanjang waktu dengan jumlah debit air sesuai dengan musim yang ada pada wilayah DAS tersebut dan hampir setiap tahun pada saat musim penghujan aliran airnya sering meluap.

Berdasarkan garis besarnya meluapnya sungai Bolango disebabkan oleh beberapa faktor yakni kondisi daerah hulunya sudah tidak alami lagi akibat penggunaan lahan oleh manusia, kondisi daerah hilir yang sudah tidak sesuai dimana daya tampung volume air tidak memadai karena daerah bibir sungai sudah sempit oleh pemukiman penduduk.

Pertumbuhan penduduk yang sangat pesat yang diiringi dengan tekanan kebutuhan penduduk yang tinggi, menyebabkan kerusakan kelestarian hutan yang merupakan tempat dimana proses daur hidrologi berlangsung. Kerusakan hutan menyebabkan daur hidrologi rusak dan menyebabkan debit sungai merosot sekali disaat musim kemarau dan dimusim penghujan debit air meningkat. Kekritisan DAS juga dapat dilihat dari aspek air, kekritisan ini secara sederhana dapat ditentukan oleh variabel ketersediaan air dan kebutuhan air. Daerah aliran sungai memiliki ketersediaan air yang lebih kecil dari kebutuhan, maka DAS tersebut berada dalam kondisi kritis air secara hidrologis, begitu juga sebaliknya. Informasi ini sangat penting untuk menunjang perencanaan pengelolaan DAS yang lebih baik, sehingga dapat ditentukan kegiatan-kegiatan yang dapat menyeimbangkan antara ketersediaan dan kebutuhan, bahkan diharapkan mampu meningkatkan cadangan air DAS tersebut. Untuk mengetahui DAS yang memiliki potensi ketersediaan air tercukupi, atau sudah kritis bahkan sangat kritis, dapat diketahui berdasarkan Neraca Air.

Berdasarkan uraian-uraian dan fakta lapangan tersebut di atas, mendorong penulis untuk mengadakan penelitian tentang

"ANALISIS NERACA AIR DAERAH ALIRAN SUNGAI BOLANGO”

\section{Rumusan Masalah}

1. Bagaimakah kebutuhan air di Daerah Aliran sungai Bolango ?

2. Bagaimana besar debit ketersedian air di DAS Bolango? 
3. Bagaimana keseimbangan air (neraca air ) di

DAS Bolango ?

\section{Tujuan Penelitian}

Tujuan dari penelitian ini adalah :

1. Untuk mengetahui kebutuhan air di daerah aliran sungai Bolango

2. Untuk mengetahui jumlah besar debit ketersediaan air di daerah aliran sungai Bolango

3. Untuk mengetahui neraca air di daerah aliran sungai Bolango

\section{Batasan Masalah}

Ruang lingkup dari pembahasan tugas akhir adalah:

1. Ketersediaan air dianggap tetap sampai tahun 2020

2. Perhitungan kebutuhan air hanya memperhitungkan domestic dan kebutuhan air untuk irigasi di daerah Kota Gorontalo.

3. Jumlah penduduk Kota Gorontalo diproyeksikan sampai dengan tahun 2020.

4. Neraca air diproyeksikan tahun 2014 sampai dengan 2020.

\section{Manfaat Penelitian}

1. Manfaat Teoritis

Dapat menjadi masukan tambahan dalam menambah wawasan kajian ilmiah bagi para mahasiswa teknik sipil serta dapat memberikan berupa tambahan sumbangan dalam ilmu kategori ilmu teknis.

2. Manfaat Praktis

Dengan adanya penelitian ini besar harapan agar dapat memberikan informasi tentang kebutuhan dan ketersediaan air di daerah aliran sungai Bolango serta menjadi masukan kajian kepada instansi pelaksana yang bertugas dan bertanggung jawab pada wilayah sungai Bolango terutama yang ada di wilayah Kota Gorontalo.

\section{LANDASAN TEORI}

\section{- Siklus Hidrologi}

Siklus hidrologi merupakan proses kontinyu, dimana keadaan air bergerak dari bumi ke atmosfer dan kemudian kembali ke bumi lagi. Hujan yang jatuh sebagian tertahan oleh tumbuhan dan selebihnya sampai ke permukaan tanah. Sebagian air hujan yang sampai ke permukaan tanah akan meresap sampai ke dalam tanah (infiltrasi) dan sebagian lainnya mengalir di atas permukaan tanah (suface runoff). Air yang meresap ke dalam tanah sebagian mengalir di dalam tanah (perkolasi) yang kemudian keluar sebagai mata air atau mengalir ke sungai dan akhirnya ke laut, siklus ini berlangsung terus menerus (lihat Gambar 1)

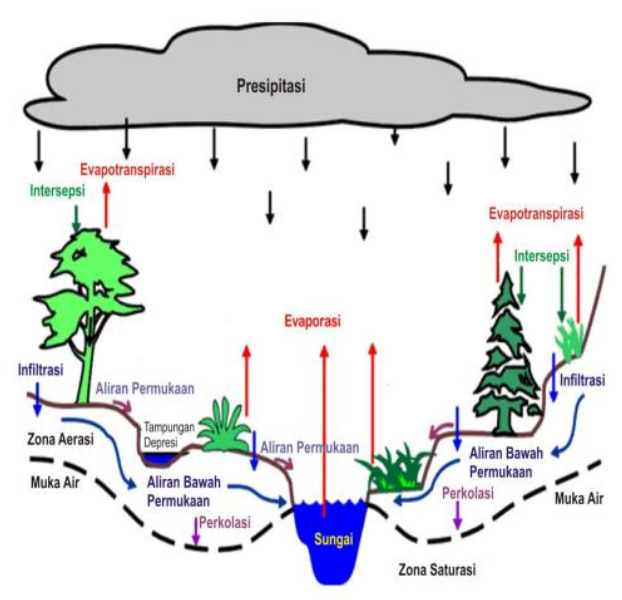

Gambar 1. Siklus Hidrologi

\section{- Evapotranspirasi Potensial}


Evapotranspirasi potensial merupakan banyaknya air yang dilepas ke udara dalam bentuk uap air yang dihasilkan dari proses evaporasi dan transpirasi. Suatu proses perubahan molekul air dalam wujud cair ke wujud gas, ini dinamakan dengan evaporasi/penguapan. Evaporasi potensial dihitung dengan menggunakan metode penman modifikasi yang memerlukan data letak lintang, temperatur, kelembaban udara, presentasi penyinaran matahari dan kecepatan angin. Besaran evapotranspirasi untuk lokasi genangan, daerah irigasi dan daerah pengaliran yang didapat merupakan evapotranspirasin aktual. (Wanielista, 1990)

Data terukur yang akan dibutuhkan :

- Suhu rerata bulanan $(\mathrm{t})$

- Kelembaban relative bulanan rerata (RH)

- Kecerahan matahari bulanan rerata $(\mathrm{n} / \mathrm{N})$

- Letak lintang daerah (LL)

- Angka koreks

Persamaan Penman dirumuskan sebagai berikut :

$E t o=c\left[W \cdot R_{n}+(1+W) \cdot f(U) \cdot(e a-e d)\right.$

\section{- Debit Aliran Air Masuk (Inflow) Metode F.J. Mock}

Metode sederhana dan simulasi keseimbangan air bulanan untuk aliran yang meliputi data hujan, evaporasi, dan karakteristik hidrologi daerah pengaliran, metode ini diperkenalkan Dr. F.J. Mock tahun 1973, Kriteria perhitungan dengan asumsi yang digunakan dalam analisa ini adalah:
- (Eto) Evapotranspirasi actual dihitung dari evaporasi potensial metode Peman. Hubungan antara Evaporasi potensial dengan

Evapotranspirasi aktual dihitung dengan rumus

$$
\begin{aligned}
\mathrm{Ea} & =\mathrm{Eto}-\Delta \mathrm{E} \rightarrow(\mathrm{Ea}=\mathrm{Et}) \\
\Delta \mathrm{E} & =\operatorname{Eto} \mathrm{x}(\mathrm{m} / 20) \times(18-\mathrm{n})
\end{aligned}
$$

\section{- Keseimbangan Air Permukaan Tanah}

Air hujan yang akan sampai kepermukaan tanah dapat dirumuskan sebagai berikut :

$$
\mathrm{Ds}=\mathrm{P}-\mathrm{Et}
$$

Perubahan Kandungan air tanah (soil storage) apabila harga Ds negative maka kapasitas kelembaban tanah akan berkurang dan bila Ds positif akan menambah kekurangan kapasitas kelembaban tanah pada bulan sebelumnnya. Kapasitas kelembaban (Soil Moisture Capacity) perkiraan kapasitas kelembaban awal tanah yang diperlukan pada saat dimulainya simulasi dan besarnya tergantung dari kondisi porositas lapisan tanah atas dari daerah pengaliran. Pengambilan sampel $50 \mathrm{~s} / \mathrm{d}$ $250 \mathrm{~mm}$, yakni kapasitas kandungan air dalam tanah per $\mathrm{m}^{3}$. Kelembaban makin besar apabila porositas tanah lapisan atas besar.

\section{- Keseimbangan Air Permukaan Tanah}

Air hujan yang akan sampai kepermukaan tanah dapat dirumuskan sebagai berikut :

$$
\mathrm{Ds}=\mathrm{P}-\mathrm{Et}
$$

Dengan :

Ds = Air hujan yang mencapai permukaan tanah ( $\mathrm{mm} / \mathrm{hari})$

$\mathrm{P}=$ Curah hujan $(\mathrm{mm} /$ hari)

Et $=$ Evapotranspirasi terbatas $(\mathrm{mm} / \mathrm{hari})$ 
Perubahan Kandungan air tanah (soil storage) apabila harga Ds negative maka kapasitas kelembaban tanah akan berkurang dan bila Ds positif akan menambah kekurangan kapasitas kelembaban tanah pada bulan sebelumnnya. Kapasitas kelembaban (Soil Moisture Capacity) perkiraan kapasitas kelembaban awal tanah yang diperlukan pada saat dimulainya simulasi dan besarnya tergantung dari kondisi porositas lapisan tanah atas dari daerah pengaliran. Pengambilan sampel $50 \mathrm{~s} / \mathrm{d}$ $250 \mathrm{~mm}$, yakni kapasitas kandungan air dalam tanah per $\mathrm{m}^{3}$. Kelembaban makin besar apabila porositas tanah lapisan atas besar.

\section{- Debit Andalan Metode Weibull}

Debit andalan merupakan debit minimum sungai kemungkinan debit dapat dipenuhi ditetapkan $80 \%$, sehingga kemungkinan debit sungai lebih rendah dari debit andalan sebesar $20 \%$. Untuk mendapatkan debit andalan sungai, maka nilai debit yang dianalisis adalah dengan Metode NRECA dan Metode MOCK, menurut tahun pengamatan yang diperoleh, harus diurut dari yang terbesar sampai yang terkecil. Kemudian dihitung tingkat keandalan debit tersebut dapat terjadi, berdasarkan probabilitas kejadian mengikuti rumus Weibull.

Rumus tersebut adalah :

$$
\mathrm{P}=\frac{\mathrm{M}}{n+1} \text { dengan }
$$

Dengan demikian pengertian debit andalan $80 \%$ adalah berdasarkan pada nilai debit yang mendekati atau sama dengan nilai probabilitas (P) $80 \%$.

\section{- Ketersediaan Air}

Berdasarkan sistem siklus air, dapat di ketahui bahwa air yang berada di bumi ini merupakan hasil dari hujan (presipitasi). Air hujan di permukaan bumi jatuh di berbagai kondisi tutupan lahan, baik itu perkotaan, desa, hutan, sawah, jenis tanah yang berbeda dan topografi yang berbeda. Kondisi lahan yang berbeda akan membedakan besarnya air yang akan mengalami peresapan ke dalam tanah, penguapan, tersimpan di tajuk-tajuk pohon dan cekungan, maupun menjadi aliran langsung. Kondisi tersebut menunjukkan bahwa komponen fisik dan meteorologis memiliki pengaruh terhadap ketersediaan air (kondisi hidrologi) di suatu DAS.

\section{- Kebutuhan Air}

Kebutuhan air sebagai kebutuhan yang sangat tidak bisa dipisahkan dari kehidupan mahluk hidup, seperti yang telah diuraikan diatas, kebutuhan air sangat beragam jenisnya, berikut beberapa kebutuhan ,penggunaan air yang ada dikehidupan penduduk sekarang ini kebutuhan tersebut antara lain :

\section{Kebutuhan air irigasi}

Kebutuhan air untuk irigasi sangat diperlukan untuk menyalurkan serta membagi air ke bidang-bidang tanah pertanian secara teratur, serta membuang air kelebihan yang tidak diperlukan lagi. Pola tanam akan memberikan gambaran tentang jenis dan luas tanaman yang akan diusahakan dalam satu tahun. Pola tata tanam yang direncanakan untuk suatu daerah irigasi merupakan jadual tanam yang disesuaikan dengan ketersediaan airnya. 
Berbagai jenis tanaman mempunyai kebutuhan air yang bervariasi, bergantung pada jenis dan tahap pertumbuhan tanaman. Berbagai jenis tanaman untuk pertumbuhannya memerlukan kebutuhan air yang berbeda.

2. Kebutuhan air domestik

Untuk Menghitung kebutuhan air domestik, harus diketahui jumlah penduduk dengan kebutuhan konsumsi air yang berbeda-beda dan sesuai dengan ketetapan kebutuhan air sesuai dengan kondisi daerah yang akan dijadikan sebagai penelitian. Dalam perhitungan ini akan digunakan metode geometrik memperkirakan jumlah penduduk yang akan datang dengan rumus jumlah penduduk dalam perencanaan.

\section{- Neraca Air}

Neraca air (water balance) merupakan neraca masukan dan keluaran air disuatu tempat pada periode tertentu, sehingga dapat digunakan untuk mengetahui jumlah air tersebut kelebihan (surplus) ataupun kekurangan (defisit). Kegunaan mengetahui kondisi air pada surplus dan defisit.

Manfaat secara umum yang dapat diperoleh dari analisis neraca air antara lain (Triatmodjo, B. 2009) :

Model neraca air cukup banyak, namun yang biasa dikenal terdiri atas tiga model antara lain:

\section{- $\quad$ Model Neraca Air Umum}

Model ini menggunakan data klimatologis dan bermanfaat untuk mengetahui berlangsungnya bulan-bulan basah (jumlah curah hujan melebihi kehilangan air untuk penguapan dari permukaan tanah atau evaporasi maupun penguapan dari sistem tanaman atau transpirasi, penggabungan keduanya dikenal sebagai evapotranspirasi.

- $\quad$ Model Neraca Air Lahan

Model ini merupakan penggabungan data klimatologis dengan data tanah terutama data kadar air pada Kapasitas Lapang (KL), kadar air

tanah pada Titik Layu Permanen (TLP), dan Air Tersedia $(\mathrm{WHC}=$ Water Holding Capacity).

\section{METODE PENELITIAN}

\section{- Pengumpulan Data}

Data yang diperlukan dalam kegiatan penelitian ini terdiri atas data primer dan data sekunder seperti pada langkah pemgumpulan data-data berikut ini :

1. Data Primer

- Pengamatan langsung

- Observasi lapangan

- Wawancara dengan penduduk

- Pengambilan dokumentasi

2. Data Sekunder

- Pengumpulan data dari Kementerian Pekerjaan Umum dan Perumahan Rakyat Balai Wilayah Sungai Sulawesi II Gorontalo

- Pengumpulan data dari BPS Kota Gorontalo Adapun kegiatan-kegiatan serta jenis penelitian yang dilakukan pada tahap ini adalah:

- Pengumpulan data spasial yakni peta-peta tematik, peta dasar.

- Pengumpulan data-data hidrologi dan klimatologi yang meliputi curah hujan, 
debit dan suhu, pengumpulan data pendukung lainnya.

\section{- Tahapan Penelitian}

1. Pengambilan Data

2. Analisa Curah Hujan

3. Analisa Debit Air

4. Perhitungan Kebutuhan Air

5. Perhitungan Analisis Neraca Air DAS Bolango.

lokasi sungai Bolango dapat dilihat pada Gambar 2 di bawah ini :

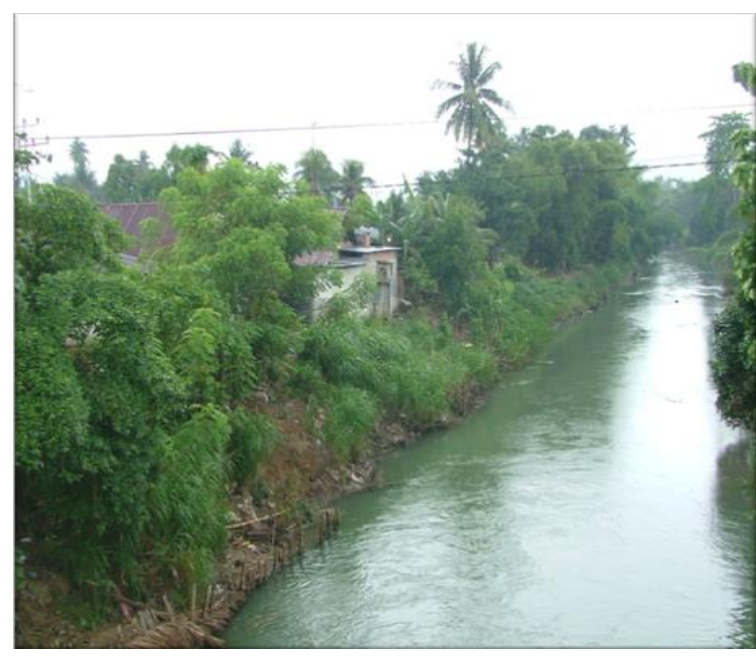

Gambar 2. Lokasi Sungai Bolango

\section{- Langkah Perhitungan}

- Analisa Curah Hujan

Hujan yang jatuh di suatu wilayah tidak seragam baik intensitas, tebal maupun lamanya hujan. Cara yang umum di pakai dalam menghitung hujan rata-rata yaitu rata-rata Aljabar.

$$
\bar{R}=\frac{1}{n}\left(R_{1}+R_{2}+\cdots R_{n}\right)
$$

- Perhitungan Debit Aliran

Perhitungan debit aliran dihitung dengan menggunakan metode F.J Mock.
Evapotranspirasi aktual dihitung dengan rumus

$$
\begin{aligned}
& \mathrm{Ea}=\text { Eto }-\Delta \mathrm{E} \rightarrow(\mathrm{Ea}=\mathrm{Et}) \\
& \Delta \mathrm{E}=\text { Eto } \times(\mathrm{m} / 20) \times(18-\mathrm{n}) \rightarrow(\mathrm{Ea}=\Delta \mathrm{E})
\end{aligned}
$$

- Analisa Kebutuhan Air

Perhitungan dengan menggunakan hitungan jumlah kebutuhan air domestik dan kebutuhan air irigasi.

\section{- Analisa Neraca air}

Untuk Mengetahui kondisi air pada keadaan surplus (lebih) dan defisit (kurang) ini sangat berguna dan untuk mengantisipasi bencanan yang kemungkinanan terjadi. Model neraca air yang dipakai yakni Model neraca air umum dimana akan dihitung adanya ( Jumlah ketersediaan air - Jumlah kebutuhan air domestik dan irigasi )

\section{HASIL DAN PEMBAHASAN}

\section{- Analisa Curah Hujan}

Curah hujan bulanan akan diperoleh dari curah hujan harian, berdasarkan pengamatan dan pencatatan stasiun hujan SWS Limboto Bolango Bone pada Pos DAS Bolango Gorontalo dengan cara menggunakan rata-rata aljabar. Dan untuk hasil tahun-tahun lainnya yang dihitung dengan cara yang sama dan hasil perhitungan selengkapnya dapat dilihat pada tabel 
Tabel 1 Jumlah Rata-rata hari hujan setiap bulan (Stasiun : Bolango Dulamayo, Bolango Boidu, Bolango Longalo, Bolango

\begin{tabular}{|c|c|c|c|c|c|c|c|c|c|c|c|c|c|c|}
\hline Tahun & Jan & Peb & Mar & Apr & Mei & Juni & Juli & Ags & Sep & Okt & Nov & Des & Jlh & Rata2 \\
\hline \multicolumn{10}{|c|}{ (mm) } \\
\hline $\mathbf{2 0 0 8}$ & 10 & 9 & 23 & 12 & 8 & 13 & 17 & 13 & 10 & 16 & 19 & 16 & 166 & 14 \\
\hline $\mathbf{2 0 0 9}$ & 18 & 11 & 12 & 14 & 11 & 4 & 6 & 3 & 1 & 9 & 19 & 7 & 116 & 10 \\
\hline $\mathbf{2 0 1 0}$ & 9 & 6 & 6 & 14 & 20 & 20 & 16 & 14 & 22 & 18 & 12 & 20 & 179 & 15 \\
\hline $\mathbf{2 0 1 1}$ & 15 & 17 & 19 & 16 & 12 & 10 & 3 & 3 & 8 & 13 & 13 & 12 & 138 & 12 \\
\hline $\mathbf{2 0 1 2}$ & 12 & 13 & 14 & 16 & 11 & 3 & 17 & 9 & 3 & 12 & 19 & 19 & 147 & 12 \\
\hline $\mathbf{2 0 1 3}$ & 10 & 15 & 9 & 19 & 19 & 9 & 17 & 13 & 7 & 5 & 15 & 19 & 157 & 13 \\
\hline Jhh & 74 & 71 & 84 & 91 & 81 & 59 & 75 & 54 & 50 & 74 & 97 & 93 & & \\
\hline Rata2 & 12 & 12 & 14 & 15 & 13 & 10 & 12 & 9 & 8 & 12 & 16 & 16 & & \\
\hline
\end{tabular}

\section{- Evapotranspirasi Potensial}

Data klimatologi yang selengkapnya dan digunakan sebagai data dapat dilihat pada lampiran dan hasil rekapitulasi data stasiun klimatologi WS Limboto-Bolango-Bone bulanan dari tahun 2009 - 2013, pada tabel 2 dan lampirannya.

Tabel 2 Hasil Rekapitulasi Rerata Data Stasiun Klimatologi WS Limboto-Bolango-Bone Provinsi Gorontalo

\begin{tabular}{|c|c|c|c|c|c|c|c|c|c|c|c|c|c|c|}
\hline \multirow{2}{*}{ Uraian } & \multirow{2}{*}{$\operatorname{sim}$} & Sat & \multicolumn{12}{|c|}{ Bulan } \\
\hline & & & Jan & Peb & Mar & Apr & Mei & Jun & Jul & Ags & Sep & $0 \mathrm{kt}$ & Nor & Des \\
\hline Temperaturu udara & $t$ & ${ }^{\circ} \mathrm{C}$ & 27.40 & 27.50 & 27,60 & 28.10 & 28.00 & 27,30 & 27,00 & 27.20 & 27.20 & 25.80 & 27.80 & 28.00 \\
\hline Kecepptan angin & U & $\mathrm{m} / \mathrm{s}$ & 0.74 & 0.69 & 0.64 & 0.59 & 0.63 & 0.63 & 0.69 & 0.72 & 0.68 & 0.70 & 0.61 & 0.65 \\
\hline Klmbn. udara & $\mathrm{RH}$ & $\%$ & 91.1 & 92 & 92.2 & 92.1 & 92 & 92.3 & 91 & 90.8 & 91.3 & 82 & 89 & 91.2 \\
\hline Sinar matahari & $\mathrm{nN}$ & $\%$ & 34.9 & 50.5 & 49 & 46 & 51.6 & 37.5 & 36.4 & 4578 & 57.4 & 44.3 & 47.65 & 39.6 \\
\hline
\end{tabular}

\section{- Analisa Debit Masuk (inflow) Metode F.J} Mock

Metode F.J Mock merupakan metode sederhana simulasi keseimbangan air bulanan untuk aliran yang meliputi hujan, evaporasi dan karakteristik hidrologi pada daerah aliran. Dalam menghitung analisa debit inflow ini, lebih dulu kita harus mengetahui data -data yang digunakan.

Hasil rekapitulasi debit inflow bulanan tahun 2009 sampai 2013 dapat dilihat pada tabel 3 dibawah ini.
Tabel 3 Hasil rekapitulasi debit inflow tahunan - Metode

\begin{tabular}{|c|c|c|c|c|c|c|c|c|c|c|c|c|}
\hline \multicolumn{13}{|c|}{ F.j Mock } \\
\hline Tahun & Jan & Peb & Mar & Apr & Mei & Jun & Jul & Ags & Sep & $0 \mathrm{kt}$ & Nov & Des \\
\hline 2009 & 26.27 & 21.105 & 22.58 & 35.95 & 28.59 & 14.76 & 9.32 & 4.34 & 2.33 & 13.27 & 25.84 & 20.80 \\
\hline 2010 & 24.75 & 15360 & 7.29 & 23.12 & 26.62 & 33.02 & 35.10 & 33.42 & 18.018 & 22.78 & 22.96 & 29.22 \\
\hline 2011 & 18.34 & 27799 & 25.82 & 22.84 & 1399 & 8.35 & 398 & 1990 & 1.32 & 11.34 & 11.05 & 13.69 \\
\hline 2012 & 31.10 & 26.32 & 20.06 & 18.22 & 15.26 & 7.99 & 22.86 & 1289 & 7.50 & 7.44 & 21.52 & 34,53 \\
\hline 2013 & 26,40 & 16.27 & 7.111 & 23.34 & 27 & 33.07 & 35.12 & 35.10 & 42.85 & 35.98 & 29,78 & 32.52 \\
\hline Jumalah & 126.86 & 107.00 & 83.47 & 124.16 & 111.19 & \begin{tabular}{|c|c|}
97.19 \\
\end{tabular} & 106.38 & 87.65 & 72.08 & 90.82 & 111.15 & 130.76 \\
\hline Rata2 & 25.37 & 21.40 & 16.69 & 24.83 & 22.24 & 19.44 & 21.28 & 17.53 & 14.42 & 18.16 & 22.23 & 26.15 \\
\hline Maks & 31.10 & 27999 & 25.82 & 3595 & 28.59 & 33.07 & 35.12 & 33.42 & 42.85 & 3598 & 29.78 & 32.52 \\
\hline \begin{tabular}{|l|} 
Min \\
\end{tabular} & 18.44 & 15.36 & 7.29 & 18.92 & 1399 & 7.99 & 3.98 & 1.90 & 1.32 & 7.44 & 11.05 & 13.6 \\
\hline
\end{tabular}

: Bolango

Sub DAS : Bolango Dulamayo, Bolango Boidu, Luas DAS : $483 \mathrm{Km}^{2}$

Bolango Longalo, Bolango Bunggalo

Tahun pengamatan : 2009-2013

Berdasarkan perhitungan akan diperoleh perhitungan debit :

- Debit inflow berkisar antara : 14,42 $\mathrm{m}^{3} /$ detik s/d 26,15 $\mathrm{m}^{3} /$ detik

- Debit inflow maksimum (Desember) : $26,15 \mathrm{~m}^{3} /$ detik

- Debit inflow minimum (September) : $14,42 \mathrm{~m}^{3} /$ detik.

\section{Analisa Debit Andalan}

Perhitungan debit andalan pada sungai Bolango akan mempergunakan metode Weibull.

Tabel. 4 Hasil perhitungan debit andalan $80 \%$

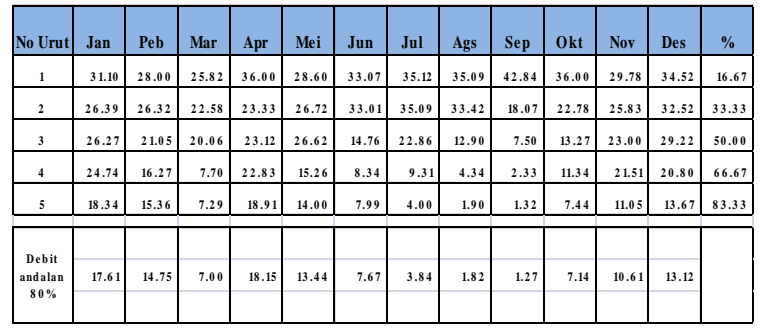

Besaran debit andalan bulanan dapat diuraikan dalam bentuk grafik dibawah ini : 


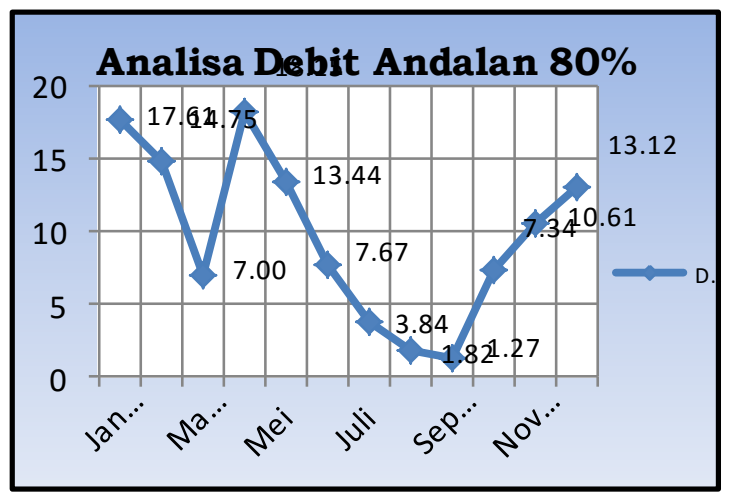

Gambar 3 Grafik Analisa Debit Andalan 80\%

Ketersediaan air untuk Daerah Aliran Sungai Bolango sesuai perhitungan diatas dapat dilihat pada Tabel 5 berikut ini :

Tabel 5 Ketersediaan Air Sungai Bolango \begin{tabular}{|r|r|c|c|c|c|c|c|c|c|c|c|c|c|}
\hline Tahun & Jan & Peb & Mar & Apr & Mei & Jun & Jul & Ags & Sep & Okt & Nov & Des & Ket \\
\hline 2009 & & & & & & & & & & & & & \\
s/d & 17.61 & 14.75 & 7.00 & 18.15 & 13.44 & 7.67 & 3.84 & 1.82 & 1.27 & 7.14 & 10.61 & 13.12 & m3/dtk \\
2013 & & & & & & & & & & & & & \\
\hline
\end{tabular}

Sumber : Hasil Perhitungan

Berdasarkan grafik diatas debit andalan untuk Sungai Bolango antara: 1,27 m3/dtk sampai dengan 18,15 m3/dtk. Dimana debit minimum pada bulan september dan debit maksimum pada bulan april.

Untuk memenuhi kebutuhan air domestik dan non domestik masyarakat terutama yang ada di derah Kota Gorontalo perhitungan ketersediaan air ini sangat diperlukan untuk menentukan neraca air pada Daerah Aliran Sungai Bolango.

Pada studi ini analisa dilakukan pada ketersediaan air permukaan, oleh sebab itu dilakukan perhitungan debit andalan dengan keandalan yang ada pada mata air yang ada dengan kapasitas dimanfaatkan bangunan irigasi. Perhitungan Debit dengan debit andalan menggunakan metode Weibull dimana debit andalan adalah $80 \%$ untuk ketersediaan air. Perhitungan analisa diatas tentunya terdapat saling keterkaitan antara perhitungan jumlah curah hujan, perhitungan jumlah debit masuk, perhitungan analisa debit andalan, analisa-analisa tersebut diatas tidak dapat dipisahkan pada perhitungan analisa neraca air.

\section{- Kebutuhan Air}

Kebutuhan Air Domestik

Pada Tabel berikut ini dapat dilihat jumlah penduduk dan rerata pertumbuhan pertahun.

Tabel 6 Rerata pertumbuhan penduduk pertahun

\begin{tabular}{|l|l|c|c|c|c|c|c|}
\hline \multirow{2}{*}{ NO } & \multirow{2}{*}{ KECAMATAN } & \multicolumn{5}{|c|}{ JUMLAH PENDUDUK KOTA GORONTALO PER TAHUN } \\
\cline { 3 - 8 } & & $\mathbf{2 0 0 8}$ & $\mathbf{2 0 0 9}$ & $\mathbf{2 0 1 0}$ & $\mathbf{2 0 1 1}$ & $\mathbf{2 0 1 2}$ & $\mathbf{2 0 1 3}$ \\
\hline 1 & KOTA BARAT & 19,767 & 20,844 & 20,220 & 22,222 & 22,804 & 22,038 \\
\hline 2 & DUNGINGI & 20,840 & 21,952 & 21,568 & 24,533 & 25,072 & 23,684 \\
\hline 3 & KOTA SELATAN & 36,084 & 38,277 & 35,988 & 23,941 & 24,433 & 22,224 \\
\hline 4 & KOTA TIMUR & 41,849 & 43,449 & 42,155 & 27,191 & 27,571 & 26,249 \\
\hline 5 & KOTA UTARA & 30,789 & 32,415 & 33,149 & 17,879 & 18,49 & 17,906 \\
\hline 6 & KOTA TENGAH & 24,538 & 25,924 & 27,047 & 27,911 & 28,837 & 26,431 \\
\hline 7 & HULONTALANGI & - & - & - & 16,902 & 17,156 & 16,304 \\
\hline 8 & DUMBO RA YA & - & - & - & 18,453 & 18,821 & 18,169 \\
\hline 9 & SIPATANA & - & - & - & 17,865 & 18,325 & 17,487 \\
\hline
\end{tabular}




\section{KESIMPULAN}

Kebutuhan air oleh seluruh makhluk hidup merupakan suatu kebutuhan yang tidak akan terpisahkan dalam kehidupan sehari-hari. Air bertransformasi melalui daur hidrologi yang dikenal sebagai sistim hidrologi dan pada Daerah Aliran Sungai (DAS) air diterima dari curah hujan yang kemudian memprosesnya sesuai dengan karakteristiknya menjadi aliran.

Pertumbuhan penduduk yang sangat pesat yang diiringi dengan tekanan kebutuhan penduduk yang tinggi, menyebabkan kerusakan kelestarian hutan yang merupakan tempat dimana proses daur hidrologi berlangsung. Kerusakan hutan menyebabkan daur hidrologi rusak dan menyebabkan debit sungai merosot sekali disaat musim kemarau dan dimusim penghujan debit air meningkat.

Debit minimum pada bulan september dan debit maksimum pada bulan april. Untuk memenuhi kebutuhan air domestik dan non domestik masyarakat terutama yang ada di derah Kota Gorontalo perhitungan ketersediaan air ini sangat diperlukan untuk menentukan neraca air pada Daerah Aliran Sungai Bolango. 1. Debit inflow berkisar antara : 14,42 $\mathrm{m}^{3} /$ detik s/d 26,15 $\mathrm{m}^{3} /$ detik, 2 . Debit inflow maksimum (Desember) : 26,15 $\mathrm{m}^{3} /$ detik, 3. Debit inflow minimum (September) : $14,42 \mathrm{~m}^{3} /$ detik.

\section{DAFTAR PUSTAKA}

Kodoatie, R.J. dan Sjarief, R. 2010. Tata Ruang Air. Yogyakarta: ANDI Yogyakarta

Triatmodjo, B. 2009. Hidrologi Terapan. Yogyakarta: Beta Offset

Wanielista, M.P., 1990. Hydrology and Water Quality Control. John Wiley \& Son FloridaUSA 